\title{
A radioecological water quality model including a multi- class sedimentary dynamics approach. Presentation and comparison with a global approach
}

\author{
O. El Ganaoui, F. Anselmet ${ }^{1}$ and P. Boyer \\ Institute of Protection and Nuclear Safety, IPSN, Department of Environmental Protection, \\ DPRE, CE Cadarache, 13108 Saint-Paul-lez-Durance, France \\ ${ }^{1}$ IRPHE, 49 rue Joliot-Curie, BP. 146, 13384 Marseille cedex 13, France
}

\begin{abstract}
The assessment of the radionuclides transfers in the physical components of rivers (water, suspended sediments, bottom sediments) involves three disciplines: hydraulics, sedimentary dynamics and radioecology. In freshwater radioecological quality models, the radioecology is linked to the sedimentary dynamics through the adsorption / desorption process and the deposition / erosion fluxes. The assessment of these fluxes requires in-situ and laboratory experiments to determine their relating parameters (settling velocity, critical shear stress of deposition and erosion, etc.). The models do not usually distinguish the different mineral particle classes and make the assumption that deposition and erosion processes cannot occur simultaneously. However, natural water flow is characterized by a wide and continuous range of different mineral particle classes. As a consequence, the assumed threshold between deposition and erosion is reduced. For example, the deposition of one class can come along with the erosion of another class. In this context, we present a radioecological model which includes a multi-class sedimentary dynamics model. To show the difference between this approach and a global one (obtained for a single average class of matter), a comparison between these two approaches concludes this paper.
\end{abstract}

\section{INTRODUCTION}

As many chemicals produced by industrial facilities, the releases of radionuclides in the river by the nuclear installations are realized in compliance with the regulations in place. In the river, one part of the radionuclides remains solute and the remainder is fixed on the suspended and on the bottom sediments. This distribution is conditioned by the dispersion process, the adsorption process and the mass exchange between suspended and bottom sediments. These latter exchanges depend on the sedimentary dynamics which influences the radionuclides transfers within the water stream. Recent works $[1,2]$ show that the adsorption of radionuclidess depends on the physical conditions, the nature and the granulometric classes of the particles, knowing that the maximal interaction concerns the cohesive sediments (diameter $<64$ $\mu \mathrm{m})$ [3]. At the same time, in a river, and depending on the flow characteristics, the dynamics of these different classes change from one class to another. To link a radioecological model to sedimentary dynamics, we must consider two main points: the adsorption and the sedimentary dynamics of the main mineral particle classes.

In this paper, we present :

(i) a radioecological water quality model including a multi class sedimentary dynamics approach.

(ii) a comparison between the present approach and a global one obtained for a single average class of matter. 


\section{RADIOECOLOGICAL WATER QUALITY MODEL PRESENTATION}

To consider the presence of several classes of particles, we use a one-dimensional radioecological model. This model includes:

- an equation for radionuclides concentration in water,

- an equation for radionuclides concentration on suspended sediment per class,

- an equation for radionuclides concentration in bottom sediment per class.

To solve these equations, we need a sedimentary dynamics and an hydraulics sub models. These models (hydraulics, sedimentary dynamics and radioecological) are explained further.

\subsection{Hydraulics model}

The hydraulics model is based on the Saint - Venant equations simplified for plain rivers $[3,4]$.

$\begin{array}{ll}\text { A mass conservation equation: } \frac{\partial A}{\partial t}+\frac{\partial(U \cdot A)}{\partial x}=0 & \text { Equation (1) } \\ \text { A momentum equation: } \frac{\partial U}{\partial t}+U \cdot \frac{\partial U}{\partial x}=-g \cdot \frac{\partial h}{\partial x}+g \cdot(I-J) & \text { Equation (2) }\end{array}$

$\begin{array}{llll}\text { Where : } & \mathbf{t} & \text { time } & \mathrm{s} \\ \mathrm{x} & \text { distance along the longitudinal axis of the watercourse } & \mathrm{m} \\ \mathrm{A} & \text { wetted cross-section } & \mathrm{m}^{2} \\ \text { U } & \text { average velocity } & \mathrm{m} \cdot \mathrm{s}^{-1} \\ \text { h } & \text { water depth } & \mathrm{m} \\ \text { I } & \text { slope } & \mathrm{m} \cdot \mathrm{m}^{-1} \\ \text { J } & \text { friction on the bed } & \mathrm{m} \cdot \mathrm{m}^{-1} \\ \text { g } & \text { gravity } & \mathrm{m.s}\end{array}$

\subsection{Sedimentary dynamics model}

The sedimentary dynamics model solves two equations by particle class C. An equation for the suspended matter concentration and an equation for the bottom sediment concentration:

$$
\begin{array}{ll}
\frac{\partial S S_{c}}{\partial t}+\frac{\partial\left(U \cdot S S_{c}\right)}{\partial \boldsymbol{x}}=\frac{1}{A} \cdot \frac{\partial}{\partial x}\left[A \cdot \boldsymbol{K} \cdot \frac{\partial S S_{c}}{\partial \boldsymbol{x}}\right]+\frac{\boldsymbol{1}}{\boldsymbol{h}} \cdot\left[\left(\boldsymbol{E}_{c}-\boldsymbol{D}_{c}\right)\right]=\mathbf{0} & \text { Equation (3) } \\
\frac{\partial \boldsymbol{B} \boldsymbol{S}_{c}}{\partial \boldsymbol{t}}=\boldsymbol{D}_{c}-\boldsymbol{E}_{c} & \text { Equation (4) }
\end{array}
$$

Where:

$\begin{array}{lll}\mathrm{SS}_{\mathrm{C}} & \text { suspended sediment concentration for the class C } & \mathrm{kg} \text { dry wet } \cdot \mathrm{m}^{3} \\ \mathrm{BS}_{\mathrm{c}} & \text { bottom sediment concentration for the class C } & \mathrm{kg} \text { dry wet } \mathrm{m}^{-2} \\ \mathrm{~K} & \text { global dispersion coefficient } & \mathrm{m}^{2} \cdot \mathrm{s}^{-1} \\ \mathrm{E}_{\mathrm{C}} & \text { erosion flux for the class C } & \mathrm{kg} \cdot \mathrm{m}^{-2} \cdot \mathrm{s}^{-1} \\ \mathrm{D}_{\mathrm{C}} & \text { deposition flux for the class C } & \mathrm{kg} \cdot \mathrm{m}^{-2} \cdot \mathrm{s}^{-1}\end{array}$

The transfers between the suspended and the bottom sediments depend on the erosion and depositioi fluxes. Their determination is presented in the following section.

\subsubsection{Erosion and deposition flux model}

This approach considers that the sediments are cohesive and that the different classes of particles do not interact. For each granulometric class, we assume that the sediment deposition is always active whatever 
the shear stress is. The sediment erosion is given by the Partheniades formula $[5,6,7,8]$. With these considerations, the deposition and erosion fluxes are respectively modelled by the following formula [9] :

$$
\begin{array}{ll}
D_{c}=W_{c} \cdot S S_{c} & \\
E_{c}=E_{o c} \cdot\left(\frac{\tau}{\tau_{c e, c}}-1\right) & \text { if } \tau_{\mathrm{f}}>\tau_{c e} \text { and } B S c>0 \\
\mathrm{E}_{\mathrm{c}}=0 & \text { if } \tau_{\mathrm{f}}<\tau_{c e} \text { or } B S C=0
\end{array}
$$

Equation (7)

Where:

$$
\begin{array}{ll}
\mathrm{W}_{\mathrm{C}} & \text { settling velocity for the class } \mathrm{C} \\
\tau & \text { shear stress } \\
\tau_{c e, c} & \text { critical shear stress of erosion for the class } \mathrm{C} \\
\mathrm{E}_{\mathrm{OC}} & \text { erosion rate for the class } \mathrm{C}
\end{array}
$$

$$
\begin{aligned}
& m . s^{-1} \\
& N \cdot m^{-2} \\
& N \cdot m^{-2} \\
& k g \cdot m^{-2} \cdot s^{-1}
\end{aligned}
$$

If the shear stress is higher than the critical shear stress of erosion of the class $\mathrm{C}$, the model converges to an equilibrium concentration, $\mathrm{SS}_{\mathrm{c}}^{*}: S S_{c}^{*}=\frac{E_{o c}}{W_{c}} \cdot\left(\frac{\tau}{\tau_{c e, c}}-1\right)$

The deposition flux is dominant when:

The erosion flux is dominant when:

$$
\begin{aligned}
& \tau_{\mathrm{f}}>\tau_{\mathrm{ce}} \text { and } \mathrm{SS}_{\mathrm{c}}>\mathrm{SS}_{\mathrm{c}}^{*} \text { or } \tau_{\mathrm{f}}<\tau_{\mathrm{ce}} . \\
& \tau_{\mathrm{f}}>\tau_{\mathrm{ce}} \text { and } \mathrm{SS}_{\mathrm{c}}<\mathrm{SS}_{\mathrm{c}}^{*} .
\end{aligned}
$$

\subsection{Radioecological model}

The model solves the equations for the radionuclides concentration in the water and on suspended and bottom sediments per particle class (time \& space).

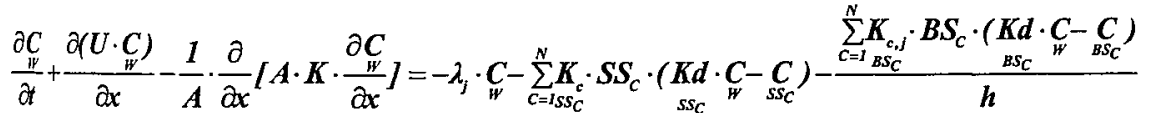

$$
\begin{aligned}
& \frac{\partial\left(S S_{c} \cdot{ }_{s S_{C}}^{C}\right)}{\partial t}+\frac{\partial\left(U \cdot S S_{c} \cdot \underset{s s_{C}}{C}\right)}{\partial x}-\frac{1}{A} \cdot \frac{\partial}{\partial x} \cdot\left[A \cdot K \cdot \frac{\partial\left(S S_{c} \cdot \underset{s S_{C}}{C}\right)}{\partial x} I=-\underset{s s_{c}}{K} \cdot\left(S S_{c} \cdot \underset{s s_{c}}{C}\right)\right. \\
& -\frac{W c}{h} \cdot\left(S S_{c} \cdot \underset{s S_{C}}{C}\right)-\lambda_{J} \cdot\left(S S_{c} \cdot \underset{s S_{C}}{C}\right)+\underset{s s_{C}}{K} \cdot \underset{s s_{C}}{K d} \cdot S S_{c} \cdot \underset{W}{C}+\frac{E_{C}}{h} \cdot \underset{B s_{C}}{C} \\
& \frac{\partial\left(B S_{c} \cdot{ }_{B S_{C}}^{C}\right)}{\partial t}=W_{c} \cdot S S_{c} \cdot{ }_{S S_{C}}^{C}-E_{C} \cdot \underset{B S_{C}}{C}-\lambda_{J} \cdot B S_{C} \cdot \underset{B S_{C}}{C}+\underset{B S_{C}}{K_{c}} \cdot B S_{C} \cdot\left(\underset{B S_{C}}{K d} \cdot \underset{H}{C}-\underset{B S_{C}}{C}\right)
\end{aligned}
$$

Where: ${ }_{\text {W }}$ Radionuclides concentration in the water Bq. $m^{-3}$

$\underset{s s c}{C} \quad$ Radionuclides concentration in the class $\mathrm{C}$ of suspended sediments $B q . k g$ dry wet ${ }^{-I}$

$\underset{B S C}{C} \quad$ Radionuclides concentration in the class $\mathrm{C}$ of bottom sediments Bq.kg dry wet ${ }^{-1}$

$\underset{S S C}{K} \quad$ Exchange rate of the interacting system "water/class C of suspended sediments"

$\underset{S S C}{K d}$ Distribution coefficient of the interacting system "water/class C of suspended sediments" $m^{3} . \mathrm{kg}^{\mathrm{K}} \mathrm{dry}$ wet ${ }^{-1}$

$\underset{b S C}{K} \quad$ Exchange rate of the interacting system "water/class C of bottom sediments" $s^{-1}$

$\underset{B S C}{K d}$ Distribution coefficient of the interacting system "water/class $\mathrm{C}$ of bottom sediments" $\mathrm{m}^{3} . \mathrm{kg} d r y$ wet ${ }^{-1}$

$\lambda \quad$ Decay constant of the radionuclides 
These equations of mass transfer are influenced by the dispersion process, the adsorption process and the mass exchange between suspended and bottom sediments.

\section{COMPARISON BETWEEN THE MULTI CLASS AND A GLOBAL APPROACHES}

For the Cs, and to show the influence of the different particle classes on the computation results, te? propose a comparison of the previous approach, as applied to five classes, with a global approach. In this context, a test case is presented.

\subsection{Sedimentary dynamics parameters}

Some resuspending sediment experiments performed in a small flume tank [10] allow us to determine the critical shear stress of erosion, the erosion rate and the settling velocity for two of the particle classes [9]. For the three other classes, we only have their settling velocity, as inferred from the Stokes formula when we consider that the particles are spherical $[3,6]: W_{C}=10^{-6} \cdot D^{2}$. We have grouped in the next table the known parameters. The test case will be adapted for two situations (erosion and deposition and onl: deposition), and we explain later on the considered flow conditions corresponding to these two situations.

\begin{tabular}{|c|c|c|c|c|}
\hline Class number & Diameter $(\mu \mathrm{m})$ & $\mathrm{W}_{\mathrm{c}}$ & $\tau_{\mathrm{cc}, \mathrm{c}}$ & $\mathrm{E}_{0 \mathrm{c}}$ \\
\hline 1 & 4 & 0.000018 & 0,07 & 0,003 \\
\hline 2 & 7 & 0.000062 & 0,21 & 0,065 \\
\hline 3 & 10 & 0.0001 & - & - \\
\hline 4 & 20 & 0.0004 & - & - \\
\hline 5 & 40 & 0.0016 & - & - \\
\hline
\end{tabular}

The parameters for the global class are calculated with a weighted average.

\subsection{Adsorption - desorption parameters}

Abril and Fraga, [1] have studied the decrease with the particle size of $\mathrm{Kd}$ in the case of man-made radionuclides interacting with mineral particles. They considered the case of a perfect spherical particle with homogeneous density, $\rho$, and with a radius, $r$. They assumed that the mobile element is exchanged only over a surface layer of thickness $\zeta . C_{w}$ is the specific activity in filtered water for the studied radionuclides. $\mathrm{C}_{\mathrm{ss}}$ is its specific activity over the surface layer and $\mathrm{C}_{\mathrm{c}}$ its specific activity in the central part of the particle. They then gave a relationship between $\mathrm{Kd}$ and the given parameters as follow: $K d=\frac{C_{W^{\prime}}}{C_{s s}} \cdot\left(1-\left(1-\frac{5}{r}\right)^{3}\right)$

Equation (12)

This relation shows the $\mathrm{Kd}$ dependence on the particle size. Abril and Fraga also give some examples for the good agreement between this formula and experiments made by Al Jundi et al [11].

Based on their research and considering the Cs case, $\zeta=1,96 \mu \mathrm{m}$, and the ratio $\mathrm{C}_{\mathrm{w}} / \mathrm{C}_{\mathrm{ss}}=68 \mathrm{~m}^{3} / \mathrm{Kg}$

$\mathrm{K}_{\mathrm{c}}$ is supposed equal for suspended and bottom sediments, for Cs, $\underset{S S C}{K}=\underset{B S C}{K}=0.00053 \mathrm{~s}^{-1}$ [12]. We use these values for the test case, for which all the parameters are grouped in the following table: 


\begin{tabular}{|c|c|c|c|c|}
\hline Class number & $\underset{S S d}{K}$ & $\underset{S S c}{K}$ & $\underset{B S C}{K d}$ & $\underset{B S C}{K}$ \\
\hline 1 & 67 & 0.00053 & 67 & 0.00053 \\
\hline 2 & 62 & 0.00053 & 62 & 0.00053 \\
\hline 3 & 52 & 0.00053 & 52 & 0.00053 \\
\hline 4 & 32 & 0.00053 & 32 & 0.00053 \\
\hline 5 & 12 & 0.00053 & 12 & 0.00053 \\
\hline
\end{tabular}

The parameters of the global class are evaluated by weighted average.

\subsection{Initial and boundary conditions}

In the test case, we perform computations relative to a uniform channel, and we report the time variation results obtained in the section located at $5000 \mathrm{~m}$. In the two situations (erosion and deposition, and only deposition), we assume that we have no bottom sediment. For each class, the initial matter concentration is supposed uniform along the channel and equal to $S S_{i n i, C}=100 \mathrm{mg} / \mathrm{l}$. In the same time, the initial

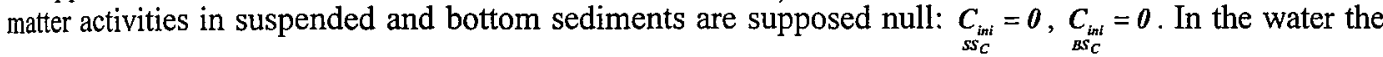
initial conditions are: $C_{i n t}=100\left(B q / \mathrm{m}^{3}\right)$. At the channel inlet, we impose a stationary boundary condition, say $S S_{C_{-} \text {entrance }}=100 \mathrm{mg} / \mathrm{l}$ per class. Concerning the activities, we take: $C_{\text {ertance }_{W}}=100\left(B q / \mathrm{m}^{3}\right)$ and

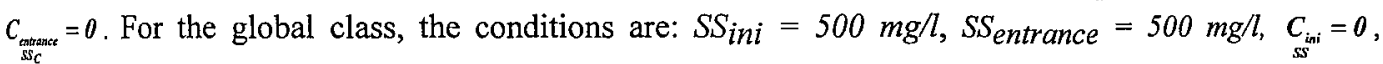

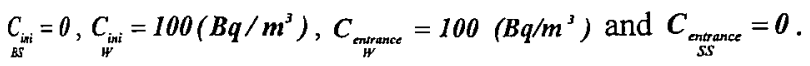

\section{RESULTS AND DISCUSSION}

\section{- Deposition case}

Deposition occurs for all particles, when the shear stress is less than the critical shear stress of erosion corresponding to the smallest particle $\tau_{\mathrm{ce}, 1}=0.07 \mathrm{~N} \cdot \mathrm{m}^{-2}$, say $\tau_{\mathrm{f}}=0.05 \mathrm{~N} \cdot \mathrm{m}^{-2}$. Figure 1 shows the obtained results.

\section{- Deposition and erosion case}

To have this situation, we set the shear stress at the value $0.25 \mathrm{~N} . \mathrm{m}^{-2}$. In this case, the erosion concern only the two first classes. Even if we do not know the erosion parameters for the three last classes, we can do the computations considering that the shear stress is not enough to cauterise these classes, i.e. their critical shear stresses of erosion are larger than that imposed by the flow. Figure 2 shows the obtained results.
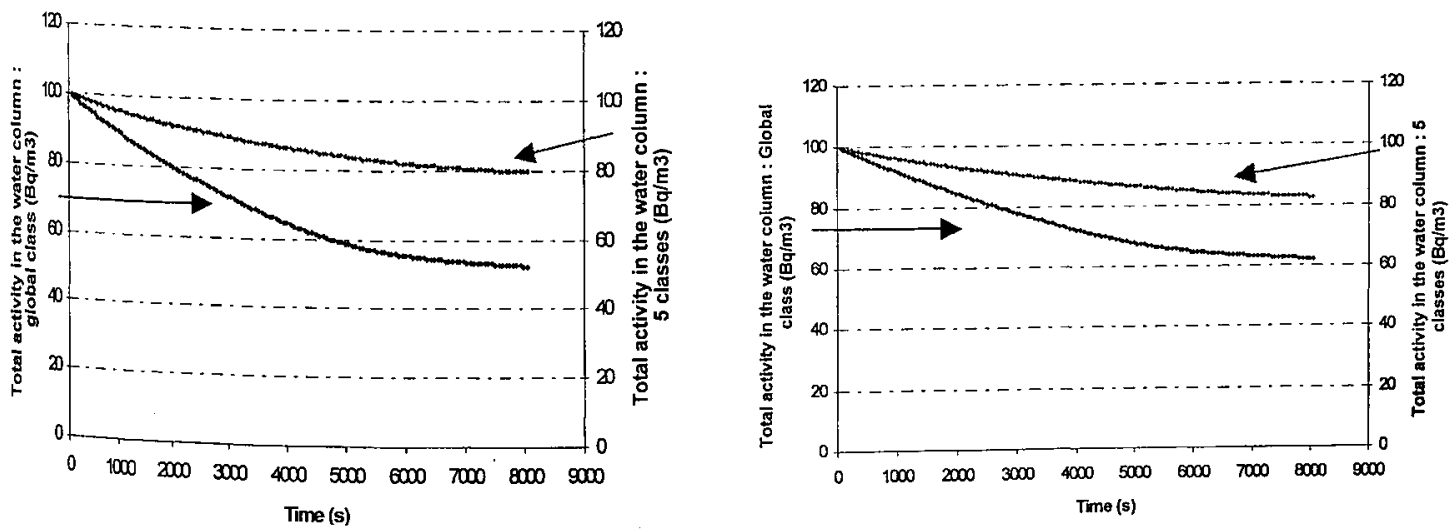


\section{- Comments on the results}

The results obtained show that the total activity in the water column is underestimated when we consider a global class.

Indeed, in the global approach, adsorption and deposition rate are equivalent for all classes, on the contrary, adsorption predominant for smaller particles and deposition for bigger particles when using multi - class approach. With this explanation, the radionuclides transfer from the water column to the bottom sediment given by the global approach is more important than the given by the multi class approach.

\section{CONCLUSIONS AND PROSPECTS}

In this paper, we were interested in a radioecological water quality model integrating sedimentary dynamics for several particle classes. We compare it to a global approach applied with only one average class of matter. The results show that the global approach assessment of the radionuclides transfer from the water column to the bottom sediment is more important. As consequence, the predicted total column water activity will be less important with a global approach than with a multi class one.

To configure the multi class model we used the spherical particle hypothesis, which allows us to infer the settling velocity from Stokes formula, whereas the $\mathrm{Kd}$ are determined by Abril and Fraga's formula [l] (also given for a spherical mineral particle). The natural water stream contains mineral and organic particles, so, in order to validate these results, we have now to extend this study to a real situation.

\section{REFERENCES}

[1] Abril J.M., Fraga E., 1996: "Some Physical and Chemical Features of the Variability of Kd Distribution Coefficient for Radionuclidess". Journal of Environmental Radioactivity 30 (3): 253-270.

[2] Borovec Z., 2000: "Element in size-fractionated bottom sediment of the Elbe River in its Czech part". Aquat. Sci.62 : 232-251.

[3] El Ganaoui O., 2000: "Transferts des effluents radioactifs dans les cours d'eau": Étude bibliographique pour la prise en compte de la dynamique sédimentaire dans les modèles de qualité radioécologique des eaux de surface." Rapport IPSN/DPRE/SERLAB N 2000/09.

[4] Viollet P.L., Chabard J.P., Esposito P., Laurence D., 1998: "Mécanique des fluides appliquée", Presses de l'École Nationale des Ponts et Chaussées.

[5] Krone B. R., 1962: "Flume studies of the transport of sediment in estuarial shoaling processes, Final report", Hydr. Engr.and San. Engr, Res. Lab, Univ. Calif. Berkeley.

[6] Migniot C., 1982: "Étude de la dynamique sédimentaire marine, fluviale et estuarienne", Thèse de Doctorat d'état. Paris-Sud.

[7] Partheniades E., 1965: "Erosion and deposition of cohesive soils", Journal of Hydraulics Division, ASCE, Vol. 91: 105-139.

[8] Villaret C., 1987: "Étude expérimentale et numérique des lois d'érosion pour des sédiments cohésifs", Thèse Doctorat, Université Scientifique de Grenoble. 
[9] EL Ganaoui O., Boyer P., Amielh M., Anselmet F., 2001: "A multi-class sedimentary dynamics model to calculate erosion and deposition fluxes in fresh water rivers, application to the low Rhone region". Proceedings of the International Association of Theoretical and Applied Limnology, Volume 28 (in press).

[10] Denis L., 1996: "Étude expérimentale de la remise en suspension du microphytos". CR Acad. Sci. Paris Life Sciences 319 : 529-535.

[11] Al-Jundi J., Randle K., Earwaker L.G., West J.R., 1993: "Factors influencing the uptake of heavy metals and radionuclidess in the Ribble estuary". Inland and Coastal Water Quality: Measurements and Modelling. Environmental Physics Conference. London.Sep. 1993.

[12] Ciffroy P., Garnier J.M., Pham Mai K., Siclet F., 1996: "Cinétiques de sorption et désorption de radioéléments sur des matières en suspension : comparaison de différents modèles". EDF, Collection de notes internes de la Direction des Etudes et Recherches. Biologie, Sciences de la terre et protection de l'environnement. 96NV00042, 14 p. 